\title{
Prevalence, Risk Factors and Microbial Profile of Surgical Site Infection after Cesarean Section in a Tertiary Care Center in Western India
}

\author{
Abhishek Kumar Jain ${ }^{1}$, Harshul Patidar², Vijay Nayak ${ }^{3}$ and Ramesh Agrawal ${ }^{4 *}$ \\ ${ }^{1}$ Department of Microbiology, Jaipur National University Institute for Medical Sciences \\ and Research Center, Jaipur - 302 017, Rajasthan, India. \\ ${ }^{2}$ Department of Pathology, N.S.C. Government Medical College, Khandwa - 450 001, Madhya Pradesh, India. \\ ${ }^{3}$ Department of Anatomy, N.S.C. Government Medical College, Khandwa - 450 001, Madhya Pradesh, India. \\ ${ }^{4}$ Department of Microbiology, N.S.C. Government Medical College, Khandwa - 450 001, Madhya Pradesh, India.
}

\begin{abstract}
Surgical site infection (SSI) was the predominant complication following cesarean delivery. Risk factors like increased Body Mass Index (BMI), emergency cesarean section (CS), prolonged hospital stay, previous CS, anemia, pre-existing chronic diseases, and failure to use preoperative antibiotic prophylaxis associated with SSI. Surgical site infections are responsible for cost burden, longer hospital stay increased maternal morbidity and mortality. Despite the advance, aseptic measures \& control practice SSI was the most common nosocomial infection. To determine the prevalence, risk factors, bacterial profile, and antimicrobial resistance pattern of SSI in women following Cesarean section at tertiary care center western India. Women who developed SSI underwent cesarean delivery enrolled in the present study. Data were collected from patient records. Collection of swab samples, identification of microorganisms, and antimicrobial susceptibility testing was done by standard CLSI guidelines Results: Prevalence of SSI was $\mathbf{1 4 . 7 \%}$ in this study. The risk factors significantly associated with SSI were emergency cesarean delivery, severe anemia, lack of preoperative antibiotics use, high Body Mass Index (BMI), preexisting disease, and previous history of CS, Klebsiella Pneumoniae \& Staphylococcus aureus was the most predominant isolates. Imipenem was the most susceptible and AmoxycillineClavulanate was the most Resistance antibiotic. Prompt identification of risk factors, microbial agents, and susceptibility patterns of SSIs are beneficial for the selection of appropriate antimicrobial therapy to prevent the emergence of drug resistance, planning to make infection control \& antibiotic policy, and taking appropriate steps to prevent risk factors.
\end{abstract}

Keywords: SSI, cesarean section, risk factors, microbial profile, antibiotic resistance

*Correspondence: drrameshagrawal22@gmail.com; +91 7568775748

(Received: December 23, 2021; accepted: February 3, 2022)

Citation: Jain AK, Patidar H, Nayak V, Agrawal R. Prevalence, Risk Factors and Microbial Profile of Surgical Site Infection after Cesarean Section in a Tertiary Care Center in Western India. J Pure Appl Microbiol. 2022;16(1):700-707. doi: 10.22207/ JPAM.16.1.73

(C) The Author(s) 2022. Open Access. This article is distributed under the terms of the Creative Commons Attribution 4.0 International License which permits unrestricted use, sharing, distribution, and reproduction in any medium, provided you give appropriate credit to the original author(s) and the source, provide a link to the Creative Commons license, and indicate if changes were made. 


\section{INTRODUCTION}

According to the center for disease control (CDC) criteria surgical site infection (SSI) is defined as an infection that occurs at the incision/operative site within 30 days after surgical procedure (cesarean section). ${ }^{1}$ Surgical site infection (SSI) was the common consequence after cesarean section (CS) in pregnant women. High cost burden, longer duration of hospital stay, dissatisfaction of patient, morbidity, and mortality of the pregnant women are the common consequences of SSI. ${ }^{2}$ The predisposing risk factors of SSI are intrinsic and extrinsic types. Intrinsic risk factors are patients related such as age, BMI (obesity or malnutrition), previous Lower Segment Cesarean Section (LSCS), and immune status of the patient. Extrinsic risk factors hospital care and management related such as antibiotic prophylaxis, type of Cesarean section (elective/emergency), duration of operation, prolong postoperative hospital stay, anemia, hypertension, and diabetes mellitus. ${ }^{3}$ SSIs can be prevented by using prophylactic antibiotics before LSCS, minimizing the operation duration, short hospital stay, and strict adherence to infection control guidelines. According to World Health Organization (WHO) prophylactic antibiotics was used before 30 to 60 minutes of Cesarean delivery. ${ }^{4}$ The commonest microorganism isolated from SSI were Staphylococcus aureus, Coagulase-Negative Staphylococcus (CONS), Streptococcus species, Enterococcus species, Klebsiella pneumoniae, Escherichia coli, Proteus mirabilis, Pseudomonas aeruginosa, Enterobacter species, and Candida albicans. $^{5-6}$

SSIs are the leading cause of maternal morbidity \& mortality in the Indian population, reduction of surgical SSIs in health care systems remains a challenge this requires a need to evaluate risk factors of SSIs. The aim and objective of this study were to evaluate various risk factors associated with SSI, identify microorganisms causing surgical site infections, and their antimicrobial susceptibility pattern in our tertiary care hospital

\section{MATERIALS AND METHODS Study design \& study population}

This was an analytical cross-sectional study conducted in the department of microbiology, Dr. S.
N. Medical College \& associated hospital, Jodhpur, Rajasthan. The study period was 18 months from January 2014 to June 2015. All pregnant women who underwent Caesarian delivery and developed SSI (within 30 days of CS according to $C D C$ ) were enrolled in the study.

\section{Data collection}

Socio-demographic data were collected from the patients and hospital records (admission files). Data for various associated risk factors were studied from history, previous discharge papers, present admission papers, and investigation reports. Specimen Collection and processing: Two Swabs samples were collected from the consented infected surgical site. First one was for direct microscopy and second swab was used for culture-sensitivity testing. The swabs were collected by a trained health worker using proper sterile precautions before wound dressing. All the collected swabs were leveled and immediately transported to the microbiology laboratory with a filled sample requisition form.

\section{Microorganism identification}

The study was concerned for the isolation of aerobic bacteria. All the received swab samples were cultured on blood and Mac- Conkey's agar medium. The inoculated culture plates were incubated at $37^{\circ} \mathrm{C}$ for $18-24$ hours, maximum incubation time were 48 hours for detection of fastidious organism. Gram's staining, colony morphology and standard biochemical tests (Catalase test, Coagulase test, Oxidase test, Indole test, Methyl red test, citrate test, urease test and triple sugar iron test) was the key elements of detection of bacterial isolates. Final confirmation \& Identification of microorganisms were done by standard CLSI guidelines. ${ }^{7}$

\section{Antimicrobial Susceptibility testing}

Kirby-Bauer disc diffusion method was used for studied of Antibiotic susceptibility pattern of the bacterial isolates according to the Clinical Laboratory Standards Institute (CLSI) guidelines. ${ }^{8}$ $0.5 \mathrm{McFarland}$ standard suspension from isolated bacterial colonies was used for antimicrobial susceptibility testing (AST). Interpretation of Antimicrobial Susceptibility testing was done as per standard protocol by measuring inhibition zone diameter around the discs and reported as sensitive, intermediate, or resistant. ${ }^{9,10}$ 
Table 1. Socio-demographic variable of women who underwent LSCS

\begin{tabular}{|c|c|c|c|}
\hline Variables & $\begin{array}{l}\text { SSI present } \\
\quad(n=280)\end{array}$ & $\begin{array}{c}\text { SSI absent } \\
(n=1615)\end{array}$ & P-Value \\
\hline \multicolumn{4}{|l|}{ Age groups } \\
\hline $18-22$ yrs $(n=594)$ & $86(14.5 \%)$ & $508(85.5 \%)$ & 0.624 \\
\hline $23-27 y r s \quad(n=721)$ & $116(16.1 \%)$ & 605 (83.9\%) & \\
\hline $28-32$ yrs $(n=374)$ & $48(12.8 \%)$ & $326(87.2 \%)$ & \\
\hline $33-37$ yrs $(n=148)$ & $20(13.5 \%)$ & $128(86.5 \%)$ & \\
\hline$>37$ yrs $(n=58)$ & $10(17.3 \%)$ & $48(82.7 \%)$ & \\
\hline \multicolumn{4}{|l|}{ Geographical area } \\
\hline Rural ( $n=1517)$ & $229(15.1 \%)$ & 1288 (84.9\%) & 0.431 \\
\hline Urban $(n=378)$ & $51(13.5 \%)$ & 327 (86.5\%) & \\
\hline \multicolumn{4}{|l|}{ Parity } \\
\hline Primipara $(n=817)$ & $125(15.3 \%)$ & $692(84.7 \%)$ & 0.575 \\
\hline Multiparous ( $n=1078)$ & 155 (14.4\%) & $923(86.6 \%)$ & \\
\hline
\end{tabular}

\section{Statistical analysis}

We have compiled the all data on an excel sheet and statistically analysis was done by using SPSS version 20. The proportion of those with SSI was estimated to determine the prevalence of SSI after CS in the study. The comparison between the two groups was made by applying a Pearson chisquare $\chi^{2}$, test. We were considered statistically significant when .P-value was $<0.05$.

\section{RESULTS}

A total of 1895 lower segment caesarian sections of pregnant women was conducted during the study period; out of which 280 (14.7\%) developed SSIs following Cesarean Section. The age group of patients was 18 to 42 years; Most of them $(41.7 \%)$ were belonging to $23-27$ years age groups. Maximum percentage of SSI was found in advanced age (>37 yrs). The Majority of the patients $81.7 \%$ was belong to rural geographical areas; SSI was also more in rural areas. Primipara women were found more SSI as compared to Multiparous women. (Table 1). Microorganism was isolated in $90.7 \%$ (254/280) of total SSI cases, amongst that Gram negative bacteria were predominantly isolated in $63 \%$ cases. Klebsiella pneumoniae was predominant bacterial isolate (24.4\%) followed by Staphylococcus aureus (22.1\%). Details shown in Table 2.

\section{Risk factor analysis}

Risk factors showing a significant association $(p<0.05)$ were increasing age, emergency cesarean delivery, high (>25) body
Table 2. Bacteriological profile of SSIs after LSCS

\begin{tabular}{lcc}
\hline Bacteriological profile & Frequency & Percentage \\
\hline Staphylococcus aureus & 56 & 22.1 \\
Coagulase negative & 25 & 9.8 \\
Staphylococcus & & \\
Enterococcus spp. & 9 & 3.5 \\
Escherichia coli & 46 & 18.2 \\
Klebsiella spp. & 62 & 24.4 \\
Citrobacter freundii & 7 & 2.7 \\
Enterobacter spp. & 6 & 2.4 \\
Proteus vulgaris & 8 & 3.1 \\
Pseudomonas aeruginosa & 26 & 10.3 \\
Acinetobacter spp. & 5 & 1.9 \\
Bacillus & 4 & 1.6 \\
Total isolates & 254 & 100 \\
\hline
\end{tabular}

mass index, anemia, prolonged hospital stay, failure of timely antibiotic prophylaxis, preexisting medical illness, and previous history of cesarean section. The detailed description of risk factor analysis is shown in Table 3. Among gram positive bacteria methicillin was the highly resistant and linezolid was the least resistant antibiotic (Table 4), whereas among gram negative bacterial isolate amoxicillin-clavulanate was the most resistant and imipenem was the most sensitive antibiotic (Table 5).

\section{DISCUSSION}

Surgical site infection (SSI) is the most common complication after cesarean delivery. The increasing incidence of SSI despite the introduction of new $\&$ advanced aseptic techniques was still a 
Table 3. Risk factor analysis of SSIs

\begin{tabular}{|c|c|c|c|}
\hline $\begin{array}{l}\text { Risk factor } \\
\text { present }\end{array}$ & $\begin{array}{l}\text { SSI present } \\
(280)\end{array}$ & $\begin{array}{c}\text { SSI absent } \\
(1615)\end{array}$ & $P$ value \\
\hline \multicolumn{4}{|l|}{ BMI } \\
\hline$\geq 25$ & 62 (23.2\%) & 206 (76.8\%) & 0.000032 \\
\hline$<25$ & $218(13.4 \%)$ & 1409 (86.6\%) & \\
\hline \multicolumn{4}{|l|}{ Type of LSCS } \\
\hline Emergency & 179 (63.9\%) & 896 (55.4\%) & 0.0084 \\
\hline Elective & $101(36.1 \%)$ & 719 (44.6\%) & \\
\hline \multicolumn{4}{|l|}{ Previous LSCS } \\
\hline Yes & $160(57.2 \%)$ & 792 (49.1\%) & 0.012 \\
\hline No & $120(42.8 \%)$ & 823 (50.9\%) & \\
\hline \multicolumn{4}{|l|}{$\begin{array}{l}\text { Duration of } \\
\text { preoperative } \\
\text { hospital stay }\end{array}$} \\
\hline $\begin{array}{l}\text { > } 4 \text { days } \\
\text { (prolonged) }\end{array}$ & 195 (69.7\%) & 783 (48.4\%) & $<0.00001$ \\
\hline$\leq 4$ days & 85 (30.3\%) & 832 (51.6\%) & \\
\hline $\begin{array}{l}\text { Duration of } \\
\text { postoperative } \\
\text { hospital stay }\end{array}$ & & & \\
\hline $\begin{array}{l}>4 \text { days } \\
\text { (prolonged) }\end{array}$ & 203 (72.5\%) & 759 (46.9\%) & $<0.00001$ \\
\hline$\leq 4$ days & 77 (27.5\%) & 856 (53.1\%) & \\
\hline $\begin{array}{l}\text { Pre-operative } \\
\text { antibiotic } \\
\text { prophylaxis }\end{array}$ & & & \\
\hline Given & 226 (80.7\%) & 992 (61.4\%) & $<0.00001$ \\
\hline $\begin{array}{l}\text { Not given } \\
\text { Preexisting } \\
\text { medical illness }\end{array}$ & $54(19.3 \%)$ & 623 (38.6\%) & \\
\hline Present & 149 (53.2\%) & 787 (48.7\%) & 0.165 \\
\hline $\begin{array}{l}\text { Absent } \\
\text { Anemia }\end{array}$ & 131 (46.8\%) & 828 (51.3\%) & \\
\hline $\begin{array}{l}\text { Present } \\
(\mathrm{Hb}<11 \mathrm{~g} \%)\end{array}$ & 206 (73.6\%) & 848 (52.5\%) & $<0.00001$ \\
\hline $\begin{array}{l}\text { Absent } \\
(\mathrm{Hb} \geq 11 \mathrm{~g} \%)\end{array}$ & 74 (26.4\%) & 767 (47.5\%) & \\
\hline
\end{tabular}

major health concern. Rapid management of SSI by early detection of microbial pathogens and selection of an appropriate antibiotic minimize the prolonged hospital stay, financial cost burden, morbidity, and mortality of the women.

\section{Prevalence of SSI}

a total of 280 women who developed SSI after cesarean delivery enrolled in the present study, out of that microorganism was isolated in 254 (90.7\%) women, 9.3\% was sterile this may be due to post-operative antibiotics therapy or collection of the sample immediately after cleaning of infection site by antiseptics solution.
The global range of SSI is very wide. This study observed prevalence of SSI was $14.7 \%$ compared to many other studies like Jasim et al., ${ }^{11}$ Nikita Dhote et al., ${ }^{12}$ Aidyn G. Salmanov et al., ${ }^{13}$ discordance to our study Meo et al., ${ }^{14}$, Ketcheson F et al., ${ }^{15}$ Moulton LJ et al. ${ }^{16}$ and Noronha et al. ${ }^{17}$ observed very low (1.9\% to $6.9 \%$ ) prevalence of SSI and De Nardo $\mathrm{P}$ et al. ${ }^{18}$ found very high $48 \%$ prevalence of SSI. The difference of SSI prevalence could be due to different study samples, use of antibiotics, preexisting disease, data used for analysis.

\section{Demographic variables}

In our study majority $(81.5 \%)$ of the patients belongs to rural residential areas which were concordant to Joseph Ngonzi, et al. ${ }^{19}$ Prevalence of SSI was also high in the rural area as compared to urban but statically not significant $(P>0.05)$. We have observed that SSI was more in Primipara as compared to Multiparous women but it is statically not significant $(P>0.05)$. Most of the women were in 23 to 27 years age group which aligned with the Dahiya, et al. ${ }^{20}$ Increase prevalence of SSI with increasing age was observed in our study; though it was statically not significant ( $P>0.05$ ) but still consistent with other studies like Zejnullahu et al. ${ }^{21}$ and Kochhal $\mathrm{N}$ et al. ${ }^{22}$ this might be due to age is a non-modifiable risk factor, decrease host immunity, reduce the ability of cell growth and repair, more risk factors and comorbidities involved in advance age group.

\section{Risk factors}

In our study many risk factors like anemia, prolonged hospital stay, failure to receive antimicrobial prophylaxis, emergency CS, previous Caesarian delivery, and underlined diseases associated with SSI. In our study increased BMI (>25) has been significantly associated with SSI $(P<0.05)$ comparable with Jasim et al. ${ }^{11}$ and Walberg M et al. ${ }^{23}$ This may be due to obese women requiring longer surgical incisions, therefore, more tissue is exposed for contamination, suturing in the subcutaneous tissue is also difficult, wound healing delay because of poor perfusion of adipose tissue, decrease the local immune response, and standard dose of prophylactic antibiotics not achieved tissue concentrations. In the present study, women who underwent emergency CS were significantly associated with SSI $(P<0.05)$ accordance to Devjani De et al.(24) \& Sway et al. ${ }^{25}$ In the current study, Emergency CS was more than elective is naturally 
Table 4. Antibiotic resistance patterns of gram positive bacteria

\begin{tabular}{|c|c|c|c|c|c|c|c|c|c|c|c|c|}
\hline \multirow[t]{2}{*}{ Organism } & \multicolumn{12}{|c|}{ Percentage of antibiotic resistance } \\
\hline & AMX & AZM & CIP & COT & $\mathrm{E}$ & CFM & $\mathrm{Cp}$ & GEN & TE & M & LZ & VA \\
\hline $\begin{array}{l}\text { Staphylococcus } \\
\text { aureus }\end{array}$ & 53.6 & 37.5 & 21.4 & 39.3 & 16 & 60.7 & 51.7 & 33.9 & 17.8 & 76.8 & 7.2 & 28.5 \\
\hline $\begin{array}{l}\text { Coagulase } \\
\text { negative } \\
\text { staphylococcus }\end{array}$ & 60 & 32 & 28 & 40 & 20 & 48 & 44 & 36 & 16 & 60 & 12 & 20 \\
\hline $\begin{array}{l}\text { Enterococcus } \\
\text { spp. }\end{array}$ & 55.5 & 33.4 & 22.3 & 44.5 & 22.2 & 55.5 & 44.4 & 33.3 & 22.2 & - & 11.2 & 33.4 \\
\hline
\end{tabular}

AMX: amoxicillin, AZM: azithromycin, CIP: ciprofloxacin, COT: cotrimoxazole, E: erythromycin, CFM: cefixime, Cp: cephalexin, GEN: gentamycin, TE: tetracycline, M: methicillin, LZ: linezolid, VA: Vancomycin.

Table 5. Antibiotic resistance patterns of gram negative bacteria

\begin{tabular}{|c|c|c|c|c|c|c|c|c|c|c|c|c|}
\hline \multirow[t]{2}{*}{ Organism } & \multicolumn{9}{|c|}{ Percentage of antibiotic resistance } & \multirow[b]{2}{*}{ COT } & \multirow[b]{2}{*}{ NT } & \multirow[b]{2}{*}{ GEN } \\
\hline & $\overline{A K}$ & CTR & CAZ & $\mathrm{CIP}$ & OF & AMC & AT & CPM & IPM & & & \\
\hline Escherichia coli & 47.8 & 60.8 & 39.2 & 43.4 & 34.7 & 65.2 & 30.4 & 17.4 & 13.0 & 52.1 & 36.9 & 56.5 \\
\hline Klebsiella spp. & 54.8 & 62.9 & 45.2 & 48.3 & 41.9 & 61.2 & 37.0 & 30.6 & 29.1 & 45.5 & 30.6 & 58.0 \\
\hline Citrobacter freundii & 42.8 & 57.1 & 42.8 & 28.5 & 28.5 & 71.4 & 42.8 & 57.1 & 28.5 & 42.8 & 28.5 & 28.5 \\
\hline Proteus vulgaris & 50.0 & 62.5 & 37.5 & 50.0 & 37.5 & 75.0 & 25.0 & 25.0 & 12.5 & 50.0 & 37.5 & 62.5 \\
\hline $\begin{array}{l}\text { Pseudomonas } \\
\text { aeruginosa }\end{array}$ & 55.8 & 57.6 & 46.4 & 61.5 & 53.8 & 65.3 & 42.3 & 38.5 & 34.6 & 57.7 & 30.7 & 61.5 \\
\hline Acinetobacter spp. & 60.0 & 40.0 & 40.0 & 60.0 & 20.0 & 80.0 & 20.0 & 40.0 & 20.0 & 40.0 & 20.0 & 60.0 \\
\hline Enterobacter & 66.6 & 50.0 & 33.4 & 50.0 & 33.4 & 66.6 & 33.3 & 16.6 & 33.4 & 50.0 & 33.4 & 50.5 \\
\hline
\end{tabular}

AK: amikacin, CTR: ceftriaxone, CAZ: ceftazidime, CIP: ciprofloxacin. OF: ofloxacin, AMC: amoxicillin-clavulanic acid, AT: aztreonam, CPM: cefepime, IPM: imipenem, COT: cotrimoxazole, NT: netilmicin, GEN: gentamycin.

expected because of the study hospital is a tertiary care referral center for high-risk pregnancies. More risk of SSI in emergency CS may be due to inadequate preoperative preparation time. In our study anemia was significantly associated with the SSI $(P<0.05)$ similar finding was observed by Molla et al., ${ }^{26}$ Rano $R$ et al. ${ }^{27}$ \& Ayala et al.. ${ }^{28}$ Anemia or high blood loss is usually associated with hypo-perfusion of the wound lead to delayed wound healing, tissue damage from prolonged retraction, reduced post-operative ambulation. Reduces oxygen tension in the wound as well as reduces local resistance mechanisms. This study was found a significant relationship between prolonged pre and post-operative hospital stay and SSI $(P<0.05)$ concordance to study done by Lamichhane $S$ et al. ${ }^{29}$ Jasim et al. ${ }^{11}$ Prolonged stay enhanced SSI might be due to more exposure to the hospital environment, risk of nosocomial infection, exposure to multidrug resistance microorganisms, and frequent diagnostic \& therapeutics procedures. Prophylactic antibiotics should be given before 02 hours of surgery, Failure to give pre-operative prophylactic antibiotic therapy is significantly associated with SSI $(P<0.05)$. In the present study post-operative, antibiotic therapy does not reduce the risk of SSI which was consistent with Abdel Jalil et al., ${ }^{30}$ possible reasons for this may be due to microorganism are resistant to antibiotic, given antibiotic are not appropriate, improper dose of antibiotic and high blood glucose level (uncontrolled diabetes). Pre-existing medical illness or immunocompromised status enhances the chance of SSI after cesarean delivery though not significantly associated in the current study $(P>0.05)$. Previous CS was significantly associated with $\mathrm{SSI}$ in the present study $(\mathrm{P}<0.05)$.

\section{Microbial profile}

The present study shows that gramnegative bacterial isolates (63\%) predominate in 
SSI, a similar finding observed by Gebissa et al. ${ }^{31} \&$ Njoku et al. ${ }^{32}$ isolated $70 \%$ and $62.7 \%$ respectively. Klebsiella species (24.2\%) was the commonest isolated pathogen followed by Staphylococcus aureus in the current study. acinetobacter was the least common (1.9\%) isolate in the present study in contrast to that Cabral et al. ${ }^{33}$ found acinetobacter was the most common isolate in their study.

\section{Antimicrobial resistance pattern}

The gram-negative isolates were highly sensitive to imipenem, netilmicin, and aztreonam; highly resistant to cephalosporins, amikacin, gentamycin, and amoxicillin/clavulanate, and moderately resistant to cotrimoxazole \& fluoroquinolones concordance to Njoku et al. ${ }^{32}$ This may be because of injudicious use or misuse of antibiotics in the study setting, especially high resistance of gentamycin and amoxicillin/ clavulanate may be due to uses of these drugs by quacks without prescription. We have observed very low resistance of imipenem and netilmicin this might be due to limited exposure of these antibiotics because of their expensiveness. Among gram-positive isolates (Staphylococcus aureus \& coagulase negative staph) penicillin group of antibiotics was shown high resistance in the current study accordance to Walelign et al. ${ }^{34}$ Very high incidence of MRSA (76.8\%) reported in our study compatible to Rijal et al. ${ }^{35}$ showed 75.5\% MRSA contrary to that Chhetri M. et al.(36) reported $58.6 \%$ MRSA on their study. Overall Imipenem was the most sensitive and amoxicillin/ clavulanate was the most resistant antibiotic in our study similar findings were observed by Ezat $\mathrm{H}$ et al. $^{37}$

\section{Limitations}

There was some limitation of current study:

- Some maternal risk factors like gestation age of pregnant women, urinary tract infection, prenatal care during ANC visit, stage of labor and labor disorders were not included.

- Some other relevant risk factors like the type of anesthesia, duration of caesarian section, blood loss during surgery, and status of PROM were not included.

- Fungus and Anaerobic bacteria were not identified in present study

Recommendation

- The practice of proper aseptic technique during and after the caesarian section should provide prime support to minimizing SSI.

- Regular surveillance of risk factors of SSI and their modification strategy is necessary.

- Rational use of antibiotics and prescription of antibiotics according to AST reporting is necessary to reduce the emergence and spread of drug-resistant microorganisms.

- Proper counseling of pregnant women to take iron-folic acid supplements to increase hemoglobin levels.

- A future prospective study can established the relationship between the SSI risk factors and to analyze other significant risk factors which were left in current study

\section{CONCLUSION}

To conclude that the prevalence of SSI was found to be $14.7 \%$. Risk factors like BMI, anemia, prolonged hospital stay; failure to give preoperative antibiotics, emergency caesarian delivery, and previous CS were significantly associated with the development of SSI. Predominantly Klebsiella pneumoniae and Staphylococcus aureus was isolated from SSI. Imipenem was most sensitive and amoxicillin/clavulanate was the most resistant antibiotic. Prompt assessment of predisposing risk factors and their modification may reduce SSI rates. Early identification of micro-organisms and their susceptibility pattern might be helpful in the selection of appropriate antibiotics that decrease the cost burden of patient and maternal morbidity \& mortality.

\section{ACKNOWLEDGMENTS}

None.

\section{CONFLICT OF INTEREST}

The authors declare that there is no conflict of interest.

\section{AUTHORS' CONTRIBUTION}

AJ conceived and designed the study, conducted research, provided research materials, collected and organized data. HP provided logistics support and supervised the procedures. RA wrote initial and final draft of article, correspond the article. VN analyzed and interpreted data, reviewed and edited manuscript. 


\section{FUNDING}

None.

\section{DATA AVAILABILITY}

All datasets generated or analyzed during this study are included in the manuscript.

\section{ETHICS STATEMENT}

The study was approved by the Ethical Committee, Institutional Review Board, Dr. SN Medical College, Jodhpur, Rajasthan, India.

\section{INFORMED CONSENT}

Written informed consent was obtained from the participants before enrolling in the study.

\section{REFERENCES}

1. National Healthcare Safety Network, Centers for Disease Control and Prevention. Surgical site infection (SSI) event. http://www.cdc.gov/nhsn/pdfs/ pscmanual/ pscssicurrent.pdf. Accessed Jan 252017.

2. Olsen MA, Butler AM, Willers DM, Devkota P, Gross GA, Fraser VJ. Risk factors for surgical site infection after low transverse cesarean section. Infect Control Hosp Epidemiol. 2008;29(6):477-484. doi: 10.1086/587810

3. Vianti RA. Parity: is A Risk Factors For Surgical Site Infection In Patient With Caesarean Section?Bull. Env. Pharmacol. Life Sci. 2018;7(6):53-57. http://www. bepls.com/beplsmay2018/7.pdf

4. Smaill FM, Grivell RM. Antibiotic prophylaxis versus no prophylaxis for preventing infection after Cesarean section. Cochrane Database Syst Rev. 2014;10(10):CD007482. doi: 10.1002/14651858. CD007482.pub3

5. Cantlon CA, Stemper ME, Schwan WR, Hoffman MA, Qutaishat SS. Significant pathogens isolated from surgical site infections at a community hospital in the Midwest. Am J Infect Control. 2006;34(8):526-529. doi: 10.1016/j.ajic.2006.04.206

6. Fantahun B, Beyeh A, Atenaf A, Belay A. Bacterial isolates from wound infection and their antimicrobial susceptibility pattern in Felege Hiwot referral hospital, Northwest Ethiopia. Ethiop J Health Sci. 2009;19(3):173-177.

7. College of Physicians \& Surgeons of Saskatchewan Laboratory Quality Assurance Program. Procedures/ guidelines for the microbiology laboratory. College of Physicians \& Surgeons of Saskatchewan Laboratory Quality Assurance Program, Saskatchewan. 2010.

8. https://www.worldcat.org/title/performancestandards-for-antimicrobial-susceptibility-testingsixteenth-informational-supplement/oclc/393106970. Last accessed on 25/06/2021

9. Gelaw A, Selassie SG, Tiruneh M, Fentie M. Antimicrobial susceptibility patterns of bacterial isolates from patients with postoperative surgical site infection, health professionals and environmental samples at a tertiary level hospital, North West
Ethiopia. Int J Pharm Sci Rev Res. 2013;3(1):1-9.

10. Amare B, Abdurrahman Z, Moges B, et al. Postoperative surgical site bacterial infections and drug susceptibility patterns at Gondar University Teaching Hospital, Northwest Ethiopia. J Bacteriol Parasitol. 2011;2(8):1000126. doi: 10.4172/2155-9597.1000126

11. Jasim $\mathrm{HH}$, Sulaiman SAS, Khan AH, Dawood OT, Abdulameer $A H$, Usha R. Incidence and Risk Factors of Surgical Site Infection Among Patients Undergoing Cesarean Section. Clinical Medicine Insights: Therapeutics. 2017;9:1-7. doi: 10.1177/1179559X17725273

12. Dhote N, Nagdeo N. Bacteriological profile of surgical site infection and associated risk factors in obstetrics and Gynecology patient. Panacea Journal of Medical Sciences. 2018;8(2):66-69. doi: 10.18231/23487682.2018.0016

13. Salmanov $A G$, Vitiuk $A D$, Ishchak $O M$, et al. Surgical site infection after cesarean section in ukraine: results a multicenter study. Wiadomosci Lekarskie. 1960;74(4):934-939. doi: 10.36740/WLek202104123

14. Meo SA, Siddique S, Nawaz Q, Meo RA. Frequency and patient related risks for surgical site infection. PAFMJ. 2011;61(2)

15. Ketcheson F, Woolcott C, Allen V, Langley JM. Risk factors for surgical site infection following cesarean delivery: a retrospective cohort study. CMAJ Open. 2017;5(3):E546-E556. doi: 10.9778/cmajo.20160164

16. Moulton LJ, Munoz JL, Lachiewicz M, Liu X, Goje O. Surgical site infection after cesarean delivery: incidence and risk factors at a US academic institution. J Matern Fetal Neonatal Med. 2018;31(14):1873-1880. doi: 10.1080/14767058.2017.1330882

17. Ghosh D, Noronha JA, Barboza LA. To Assess the Incidence and Factors Predisposing to Surgical Site Infection (SSI) in Patients Who Have Undergone Caesarean Section in Tertiary Care Hospital of Udupi District, Karnataka- A Retrospective Study. Journal of Public Health Research \& Development. 2020;11(6). doi: 10.37506/ijphrd.v11i6.9772

18. Nardo PDE, Gentilotti E, Nguhuni B, et al. Postcaesarean section surgical site infections at a Tanzanian tertiary hospital: a prospective observational study. J Hosp Infect. 2016;93(4):355-359. doi: 10.1016/j. jhin.2016.02.021

19. Isanga J, Emmanuel B, Musa K, et al. The Prevalence, Risk Factors, and Bacterial Profile of Cesarean Surgical Site Infections at a University Teaching Hospital in South Western Uganda. Int J Women's Health Care. 2020;5(1):5.

20. Dahiya P, Gupta V, Pundir S, Chawla D. Study of incidence and risk factors for surgical site infection after cesarean section at first referral unit. Int $J$ Contemp Med Res. 2016;3(4):1102-1104.

21. Zejnullahu VA, Isjanovska R, Sejfija Z, Zejnullahu VA. Surgical site infections after cesarean sections at the University Clinical Center of Kosovo: rates, microbiological profile and risk factors. BMC Infect Dis. 2019;19(1):752. doi: 10.1186/s12879-019-4383-7

22. Kochhal N, Mudey GD, Choudhari SZ. A study of clinicomicrobiological profile of surgical site infections in a tertiary care hospital. Int J Adv Med. 2019;6(2):324- 
329. doi: 10.18203/2349-3933.ijam20191135

23. Opoien HK, Valbo A, Grinde-Andersen A, Walberg M. Post-cesarean surgical site infections according to $C D C$ standards: rates and risk factors. A prospective cohort study. Acta Obstet Gynecol Scand. 2007;86(9):10971102. doi: $10.1080 / 00016340701515225$

24. De D, Saxena S, Mehta G, Yadav R, Dutta R. Risk Factor Analysis and Microbial Etiology of Surgical Site Infections following Lower Segment Caesarean Section. Int J Antibiot. 2013;2013:283025. doi: $10.1155 / 2013 / 283025$

25. Sway A, Nthumba P, Solomkin J, et al. Burden of surgical site infection following cesarean section in sub-Saharan Africa: a narrative review. Int $\mathrm{J}$ Womens Health. 2019:11:309-318. doi: 10.2147/JJWH.S182362

26. Molla M, Temesgen K, Seyoum T, Melkamu M. Surgical site infection and associated factors among women underwent cesarean delivery in Debretabor General Hospital, Northwest Ethiopia: hospital based cross sectional study. BMC Pregnancy and Childbirth. 2019;19(1):317. doi: 10.1186/s12884-019-2442-0

27. Rano R, Patel PK. Analysis of risk factors associated with caesarean section surgical site infections: a case control study. Int J Reprod Contracept Obstet Gynecol. 2020;9(12):5075-5081. doi: 10.18203/2320-1770. ijrcog20205250

28. Ayala D, Tolossa T, Markos J, Yilma MT. Magnitude and factors associated with surgical site infection among mothers underwent cesarean delivery in Nekemte town public hospitals, western Ethiopia. PLOS ONE. 2021;16(4):e0250736. doi: 10.1371/journal,. pone. 0250736 .

29. Mishra RT, Adhikari K, Lamichhane S, et al. Surgical site infection following cesarean section and its associated risk factors at a tertiary care hospital in chitwan, Journal of Chitwan Medical College. 2020;10(34):4751.

30. Jalil MHA, Hammour KA, Alsous M, et al. Surgical site infections following caesarean operations at a Jordanian teaching hospital: Frequency and implicated factors. Scientific Recports. 2017;7:12210. doi: 10.1038/s41598-017-12431-2

31. Gebissa T, Bude B, Yasir M, Mekit S, Noorulla KM. Bacterial isolates and their antibiotic sensitivity pattern of surgical site infections among the surgical ward patients of Asella Referral and Teaching Hospital. Future Journal of Pharmaceutical Sciences. 2021;7(1):100. doi: 10.1186/s43094-021-00255-x

32. Njoku CO, Njoku AN. Microbiological Pattern of Surgical Site Infection Following Caesarean Section at the University of Calabar Teaching Hospital. Open Access Maced J Med Sci. 2019;14:7(9):1430-1435. doi: 10.3889/oamjms.2019.286

33. Cabral BG, Brasiliense DM, Furlaneto IP, Rodrigues YC, Lima KVB. Surgical Site Infection Following Caesarean Section by Acinetobacter Species: A Report from a Hyperendemic Setting in the Brazilian Amazon Region. Microorganisms. 2021;9(4):743. doi: 10.3390/ microorganisms 9040743

34. Dessie W, Mulugeta G, Fentaw S, Mihret A, Hassen $M$, Abebe E. Pattern of Bacterial Pathogens and Their Susceptibilitylsolated from Surgical Site Infections at Selected Referral Hospitals, Addis Ababa, Ethiopia. Int J Microbiol. 2016;2016:2418902. doi: 10.1155/2016/2418902

35. Rijal KR, Shrestha N, Pahari N, et al. Methicillin Resistant Staphylococcus Aureus in patients visiting Western Regional Hospital, Pokhara. Journal of Institute of Medicine. 2008;30(1):21-25.

36. Chhetry M, Subedi S, Ghimire S, Lamichanne S, Banerjee B, Singh GK. Antibiotic sensitivity in post cesarean surgical site infection at a tertiary care centre in eastern Nepal. Journal of Lumbini Medical College. 2016;4(2):55-59. doi: 10.22502/jlmc.v4i2.90

37. Mezal EH, Yousif AF, Hanan ZK, Jalil AT. Isolation, Assessment of Antimicrobial Sensitivity of Bacterial Pathogens from Post-Cesarean section Infection of patients in Thi-Qar Province. European Journal of Molecular \& Clinical Medicine. 2020;7(3):958-964. 